\title{
Detailed Loss Modelling of Vehicle Gearboxes
}

\author{
Clemens Schlegel \\ Schlegel Simulation GmbH \\ Freising, Germany \\ cs@schlegel-simulation.de
}

\author{
Andreas Hösl \\ BMW Group \\ Munich, Germany \\ andreas.ha.hoes1@bmw.de
}

\author{
Sergej Diel \\ University of Applied Sciences Landshut \\ Landshut, Germany \\ sergej.diel@fh-landshut.de
}

\begin{abstract}
Drag torques of gearboxes are an important part of the overall losses in today's vehicle drive trains. From measurements it is well known that overall drag torques of vehicle gearboxes vary significantly over the range of operating points and speeds, depending on the interaction of the losses of the single gearbox elements like bearings, gearings, etc. Because today's vehicle emission regulations are becoming stricter and stricter "drag torque design" of gearboxes will be even more important in the future. Prediction of losses helps to save cost (e.g. drag torque measurements), speeds up the development and allows to assess many concepts in short time.

We collected detailed semi-analytical drag models for the common gearbox components from literature and from manufacturer information and implemented them in a Modelica library. This library contains models for radial shaft seals, rotary unions, synchronizers, multi-disc clutches, helical gearings, planetary gearings, various kinds of bearings, lubrication systems and lubricant characteristics. Using this library drag torques of any vehicle gearbox may be computed for any operating condition (engaged gear, speed, torque, temperature). Simulation results for a 7 speed double clutch transmission show good correlation with measurements.
\end{abstract}

Keywords: Automotive; Gearboxes; Drag torques

\section{Introduction}

Simulation of gearboxes is used widely for e.g. gear ratio design, for investigating noise, vibration and harshness, for assessment and tuning of control strategies and similar design aspects. Gearbox components are mostly modelled ideal, without losses, because drag torques are considered as negligible for the mentioned cases. If detailed investigations with respect to fuel consumption and emissions are needed, mostly loss maps based on measurements are used, an explicit computation of gearbox losses is done rarely. Since in an early design stage measurements are not available, the loss maps have to be estimated or derived from former designs.

A lot of papers and studies on loss computation of gearbox components are available, for a survey see e.g. [1]. For some components like torque dependent losses of gears very reliable loss descriptions exist, for other components like multi-disc clutches and most of the further torque independent losses only rough estimates are available in literature.

Losses which are independent from the gearbox input torque are a major part of the overall losses in driving cycle computations (like NEDC) which are in turn an important part of any driveline assessment. Even the most advanced codes for gearbox loss computations which are generally available [2] do not or only in part take into account torque independent losses what results in reduced reliability of the computations. Losses of synchronizers, multi-disc clutches and rotary unions are rarely taken into account.

A further problem in this context is that loss computations for bearings need the forces and torques acting on the bearings as input, but no general approach to compute them for all kinds of bearings is available, because for the highly nonlinear stiffness relations of bearings no analytical descriptions are known.

\section{Losses of gearbox components}

\subsection{General considerations}

Naunheimer [3] gives a rough survey of typical overall efficiencies of vehicle gearboxes under full load: 


$\begin{array}{cccc}\text { Manual } & \text { Automatic } & \text { Mechanical } & \text { Hydrostatic } \\ \text { gearbox } & \text { gearbox } & \text { CVT } & \text { CVT } \\ 92-97 \% & 90-95 \% & 87-93 \% & 80-86 \%\end{array}$

The losses of manual and automatic gearboxes are made up of drag torques due to the following effects in each single gearbox component $\left(P_{V}\right.$ is the power loss):

- Gears: Mesh friction, swash and squeeze in splash lubrication, oil impulse in spray lubrication $\left(P_{V Z}\right)$

- Bearings: Rolling and sliding friction, lubrication losses and losses in seals $\left(P_{V L}\right)$

- Radial shaft seals: Friction between the sealing lip and the rotating shaft $\left(P_{V D}\right)$

- Rotary unions: Friction between the lateral surfaces depending on oil pressure and shear flow in the pressure chamber $\left(P_{V D D F}\right)$

- Synchronization: Fluid drag between synchronizer and friction cone $\left(P_{V S}\right)$

- Clutch: Fluid drag in wet multi-disc clutches $\left(P_{V K}\right)$

- Oil pump: Torque consumption depending on system pressure, temperature and oil viscosity $\left(P_{V N A}\right)$

The total power loss is the sum of the power losses of the single elements and can be expressed as:

$$
P_{V}=P_{V Z}+P_{V L}+P_{V D}+P_{V D D F}+P_{V S}+P_{V K}+P_{V N A}
$$

Losses of gears and bearings may be split up into a part depending on the transmitted torque and a torque independent part. Torque dependent losses occur when two surfaces which are under pressure move relatively to each other, for example in gears or bearings. These losses are depending on the force, sliding speed and the friction coefficient (which is, in turn, depending on the lubrication) in the contact area.

Torque independent losses arise even if no torque is transmitted but the shafts rotate. These kinds of losses occur for example in seals and rotary unions.

Losses in gearings and bearings dominate the overall losses of manual gearboxes. In contrast, the losses of wet multi-disc clutches in automatic gearboxes can account for even more than $50 \%$ of the total power loss.

The computed overall loss of transmitted power is used to set up an efficiency map, which may be used in other simulation models for fuel consumption investigations. In the following chapters all the listed effects influencing the total power loss are described in more detail. Since the losses are modelled physically as "torques", the equations are given with the same definition.

\subsection{Gears}

The total loss torque $M_{V Z}$ in gears can be decomposed into the torque dependent part $M_{V Z, l a}$ and the torque independent part $M_{V Z, l u}$ :

$$
M_{V Z}=M_{V Z, l a}+M_{V Z, l u}
$$

\subsubsection{Torque dependent losses}

Ohlendorf [4] introduced the first theoretical approach for the calculation of torque dependent losses in gears in 1958. The power loss in [4] is calculated on the assumption of a constant coefficient of friction $\mu_{m}$, and a constant normal force:

$$
M_{V Z, l a}=M_{a n} \mu_{m} H_{V}
$$

$M_{a n}$ is the acting torque and $H_{V}$ is the gear loss factor which takes into account the geometry of the teeth. According to Schlenk [5], $\mu_{m}$ can be expressed as:

$$
\mu_{m}=0,048\left(\frac{F_{b t} / b}{v_{\Sigma C} \rho_{r e d C}}\right)^{0,2} \eta^{-0,05} R_{a}^{0,25} X_{L}
$$

$F_{b t}$ is the tangential force at the base circle, $b$ the tooth width, $v_{\Sigma C}$ the sum speed at the operating pitch circle, $\rho_{\text {red } C}$ the reduced radius of curvature at the pitch point, $\eta$ the dynamic oil viscosity, $R_{a}$ the arithmetic mean roughness, and $X_{L}$ a factor for the oil type.

The gear loss factor $H_{v}$ was introduced by Wimmer [6]. He only depends on the gear geometry:

$$
\begin{array}{r}
H_{V}=\pi \frac{i+1}{z_{A} i \cos \beta_{b}}\left(\alpha_{0}+\alpha_{1}\left|\varepsilon_{A}\right|+\alpha_{2}\left|\varepsilon_{B}\right|+\right. \\
\left.\alpha_{3}\left|\varepsilon_{A}\right| \varepsilon_{A}+\alpha_{4}\left|\varepsilon_{B}\right| \varepsilon_{B}\right)
\end{array}
$$


$i$ is the gear ratio, $z_{A}$ is the number of teeth of the pinion, $\beta_{b}$ is the base helix angle, $\varepsilon_{A}$ and $\varepsilon_{B}$ are the contact ratios of acting and driven wheel and $\alpha_{1}$ to $\alpha_{4}$ are coefficients depending on the values of $\varepsilon_{A}$ and $\varepsilon_{B}$. The parameters $\rho_{\text {red }}$ and $v_{\Sigma C}$ are:

$$
\begin{aligned}
& \rho_{\text {redC }}=\frac{1}{2} d_{w} \sin \left(\alpha_{w t}\right) \frac{i}{(i+1)} \frac{1}{\cos \beta_{b}} \\
& v_{\Sigma C}=2 v_{t} \sin \left(\alpha_{w t}\right)
\end{aligned}
$$

with $d_{w}$ the pitch diameter, $\alpha_{w t}$ the service pressure angle and $v_{t}$ the pitch line speed.

\subsubsection{Torque independent losses}

Two kinds of lubrications are commonly used in gearboxes: Splash lubrication and spray lubrication. For splash lubricated gears the loss torque can be written as:

$$
M_{V Z, l u}=M_{V Z, Q}+M_{V Z, P l}+M_{V Z, V}
$$

In the case of spray lubrication the loss torque is defined as:

$$
M_{V Z, l u}=M_{V Z, Q}+M_{V Z, I}+M_{V Z, V}
$$

The squeeze loss $M_{V Z, Q}$ is caused by the displacement of the oil in the contact area between the teeth. $M_{V Z, P l}$ is the resistance of the gear wheel when rotating in an oil bath. The ventilation loss $M_{V Z, V}$ is the air drag due to air or oil mist. The oil stream in spray lubrication causes the impulse loss torque $M_{V Z, I}$, since it acts on the rotating wheel.

The losses of splash lubrication are in general higher compared with spray lubrication. The losses of spray lubrication will be described in more detail, because the gearbox investigated is lubricated by oil spray.

Mauz [7] gives a definition for $M_{V Z, Q}$ :

$$
\begin{gathered}
M_{V Z, Q}=4,12 C_{1} \rho Q_{e}^{0,75} r_{w} v_{t}^{0,25} b^{0,25} m_{n}^{0,25} . \\
\left(\frac{v}{v_{0}}\right)^{0,25}\left(\frac{h_{Z}}{h_{Z 0}}\right)^{0,5}
\end{gathered}
$$

Here $\rho$ is the oil density, $\dot{Q}_{e}$ is the oil volume flow, $r_{w}$ is the pitch radius, and $m_{n}$ is the normal module. The kinematic oil viscosity $v$ and the tooth height $h_{z}$ are normalized by the reference values $v_{0}$ and $h_{z 0}$. Equa- tion (2.10) is only valid for the cases $B O$ and $B U$ (see fig. 1). For the cases $A O$ and $A U$ the loss torque $M_{V Z, Q}$ is zero. The factor $C_{l}$ is a scaling factor for gravity effects, it is 1 for $B O$ and 0.9 for $B U$.
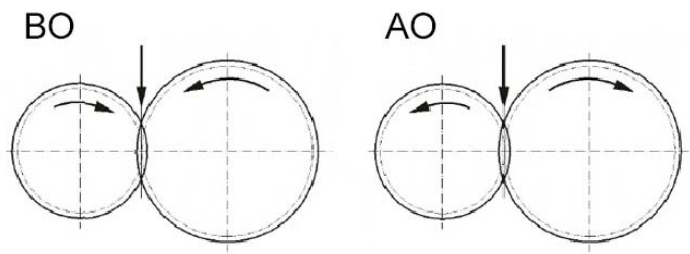

BU

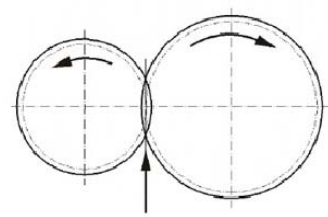

$\mathrm{AU}$

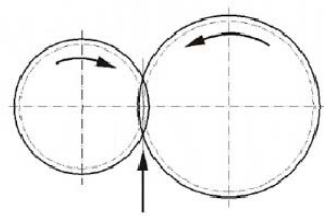

Figure 1: Different cases of spray lubrication [7]

In the cases $\mathrm{BO}$ and $\mathrm{BU}$ the spray jet hits the approaching contact area from top or from bottom, respectively. In the cases $\mathrm{AO}$ and $\mathrm{AU}$ the oil stream meets the regressing contact area. In these cases, there is almost no oil remaining on the teeth because of centrifugal forces. Therefore the loss is very small and can be neglected.

The impulse loss torque $M_{V Z, I}$ usually provides the main part of the torque independent losses in spray lubricated gears. Ariura [8] defines $M_{V Z, I}$ as:

$$
\begin{array}{ll}
M_{V Z, I}=C_{2} \rho \dot{Q}_{e} r_{w}\left(\left|v_{t}\right|-v_{s}\right) & \text { for BO, BU } \\
M_{V Z, I}=C_{2} \rho \dot{Q}_{e} r_{w}\left(\left|v_{t}\right|+v_{s}\right) & \text { for AO, AU }
\end{array}
$$

$v_{s}$ is the velocity of the oil stream. The coefficient $C_{2}$ takes into account gravitation effects. For $B O$ and $A O$ the coefficient $C_{2}$ is 1 , for $B U$ it is 0,9 and for $A U$ it is 0,85 .

According to Maurer [9], the ventilation loss torque $M_{V Z, V}$ is composed of the loss of the gear wheel itself $\left(M_{V Z, V_{Z}}\right)$ and the loss in the contact area between the teeth $\left(M_{V Z, V_{E}}\right)$ :

$$
\begin{aligned}
M_{V Z, V_{Z}} & =1,37 \cdot 10^{-9} v_{t}^{1,9} d_{w}^{1,6} b^{0,52} m_{t}^{0,69} F_{\text {Wand }} \\
M_{V Z, V_{E}} & =1,17 \cdot 10^{-6} v_{t}^{1,95} i^{0,73} b^{1,37} F_{\text {Wand }}
\end{aligned}
$$

$m_{t}$ is the transverse module and $F_{\text {Wand }}$ describes the influence of the gearbox housing. 


\subsection{Bearings}

While the forces acting on the mesh or on statically determined bearings can easily be computed from force and torque equilibrium using the transmitted torque and geometry parameters (see fig. 2), the force calculation for statically over-determined bearings requires some preprocessing.

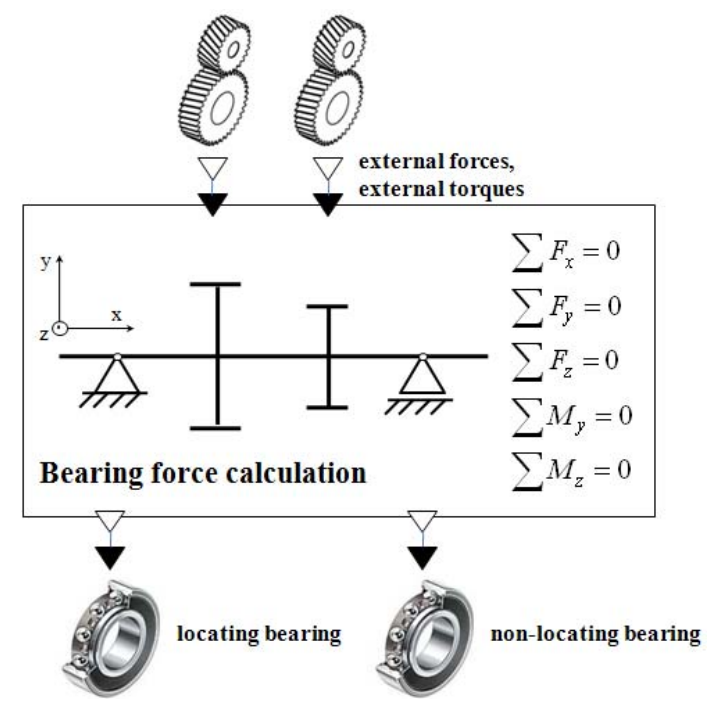

Figure 2: Model for the calculation of bearing forces of statically determined shafts

For the latter case, which is not uncommon for vehicle gearboxes, and for more detailed investigations computation of the forces and torques acting on a bearing requires detailed knowledge of the stiffness properties which are highly nonlinear for the rolling bearings commonly used.

Since manufacturers do not publish detailed stiffness data, we used a separate bearing calculation software provided by a bearing manufacturer [10] to compute for each over-determined shaft a map of bearing forces and torques depending on the transmitted torque and the gear engaged. The same procedure may be used for adjusted bearings.

Because several gearings may act on the same shaft, all single gearing forces and torques acting on a couple or triple of bearings must be collected and routed accordingly to the bearing drag computation model component.

In vehicle gearboxes, mostly rolling contact bearings are used. The respective loss computations will be described in the following sections in more detail.

Figure 3 shows six different types of losses in a rolling contact bearing: Rolling and sliding friction between rolling element and bearing rings (1 and 2), sliding friction between cage bar and bearing rings (3), sliding friction between cage and rolling element front surface (4), sliding friction between rolling element and outer ring (5), and friction between cage and rolling element (6) [11].

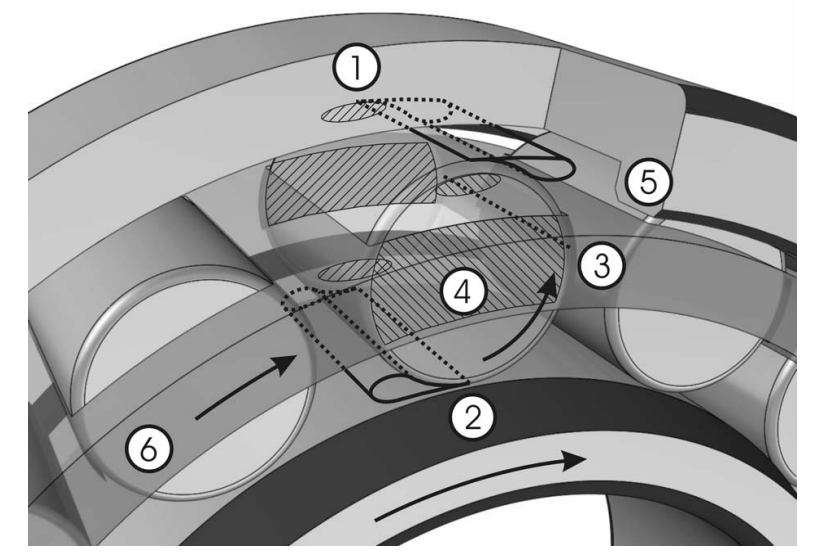

Figure 3: Different types of losses in a rolling contact bearing.

The first detailed approach to drag torque calculation of rolling contact bearings was published by Palmgren [12]. He proposed to split the drag into a torque dependent and a torque independent part. The investigations by Harris [13] and INA/FAG [14] are based on [12] and have been used for a long time. The relatively new approach by SKF [15] allows more detailed investigations because the losses are assigned to the places where they occur in the bearing.

All mentioned methods have been implemented in the library. Because of the importance of the SKFmethod it will be described shortly:

$$
M_{V L}=\phi_{i s h} \phi_{r s} M_{r r}+M_{s l}+M_{\text {seal }}+M_{d r a g}
$$

In this equation the rolling frictional torque $M_{r r}$ and the sliding frictional torque $M_{s l}$ represent the torque dependent losses. $M_{\text {seal }}$ is the frictional torque of bearing seals and $M_{\text {drag }}$ is the frictional torque due to churning, splashing etc. $M_{\text {seal }}$ and $M_{\text {drag }}$ represent the torque independent losses.

The rolling and the sliding friction torques $M_{r r}$ and $M_{s l}$ are given by:

$$
\begin{aligned}
& M_{r r}=G_{r r}(v n)^{0,6} \\
& M_{s l}=G_{s l} \mu_{s l}
\end{aligned}
$$

The variables $G_{r r}$ and $G_{s l}$ depend on the bearing type, the bearing mean diameter, the radial load $F_{r}$ and the axial load $F_{a}, n$ is the rotational speed, $v$ the kine- 
matic viscosity of the lubricant and $\mu_{s l}$ is the sliding friction coefficient.

$\phi_{i s h}$ describes the influence of the lubricating film thickness on the rolling friction. The factor $\phi_{r s}$ considers the lubricant displacement in the contact zone due to overrolling which results in a lower rolling friction torque.

The frictional torque in bearing seals is:

$$
M_{\text {seal }}=K_{S 1} d_{s}^{\beta}+K_{S 2}
$$

The constants $K_{S 1}$ and $K_{S 2}$ depend on the bearing and the seal type, $d_{s}$ is the sealing counterpart diameter and $\beta$ an exponent which depends on the bearing and seal type.

The definition of $M_{\text {drag }}$ for ball bearings is:

$$
M_{\text {drag }}=V_{m} K_{\text {ball }} d_{m}^{5} n^{2}
$$

and for roller bearings:

$$
M_{\text {drag }}=10 V_{m} K_{\text {roll }} B d_{m}^{4} n^{2}
$$

$V_{m}$ is a variable depending on the oil level, $K_{\text {ball }}$ and $K_{\text {roll }}$ are bearing type related constants, $B$ is the bearing inner ring width and $d_{m}=(D+d) / 2$ is the mean of the bearing outer diameter $D$ and the bore diameter $d$.

The SKF-method is not applicable to needle bearings. In this case other methods for example [13] or [14] may be used.

\subsection{Radial shaft seals}

The loss torque of radial shaft seals is a result of the friction between the sealing lip and the rotating shaft. For the library presented, the approaches by Linke [16] and by Kettler [17] have been used because of their simplicity compared with other approaches. The definition by Linke is:

$$
\begin{aligned}
M_{V D}= & {\left[145-1,69+350 \cdot \log \left(\log \left(v_{40^{\circ}}+0,8\right)\right)\right] . } \\
& 10^{-7} d_{w}^{2} \frac{30}{\pi}
\end{aligned}
$$

$d_{w}$ is the shaft diameter and $\vartheta$ is the temperature. Kettler gives a different formulation for the computation of the friction torque:

$$
M_{V D}=7,9163 \cdot 10^{-6} F_{D, \rho} d_{w}^{2} \frac{30}{\pi}
$$

The factor $F_{D, \rho}$ represents the effect of the temperature dependent viscosity change.

\subsection{Rotary unions}

In gearboxes rotary unions are used to permit the flow of oil to activate clutches or to transport the lubricant through the shafts from a stationary inlet to a moving part such as a rotating shaft or from one rotating shaft to another. The oil is kept within the rotary union using a (mostly rectangular) seal ring. Figure 4 shows the structure of a rotary union.

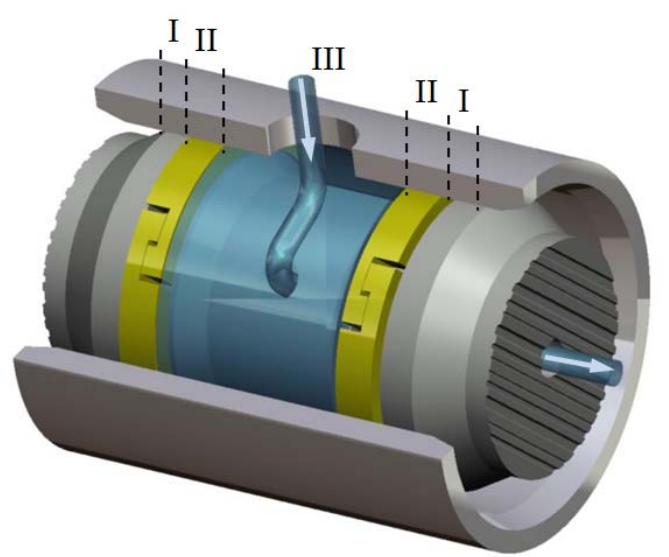

Figure 4: Structure of a rotary union

Gronitzki [18] recently investigated the losses in rotary unions in detail. He describes the loss torque as the sum of three main loss sources:

$$
M_{V D D F}=2 M_{I}+2 M_{I I}+M_{I I I}
$$

$M_{I I}$ is the friction between the seal ring and the groove (see area II in figure 4). $M_{I I I}$ (area III) is the loss torque due to the shear flow between the inner and the outer shaft in a pressurized chamber. The loss torque $M_{I}$ in area I as a result of the oil leakage is small compared to the losses in areas II and III and can therefore be neglected. For further details see [18].

\subsection{Synchronizers and clutches}

The analytical description of synchronizer losses is subject of ongoing research [19]. The results of this research are possibly also applicable to multi-disc clutches. For our implementation we used tabulated drag data for synchronizers and clutches based on measurements. 


\subsection{Oil pump}

Since no reliable models are available in literature we used measured, tabulated drag data for the oil pump. A direct calculation would be rather complex.

\section{Library implementation}

For the actual implementation of our library Modelica and the tool Dymola [20] have been used in order to easily fit into existing gearbox and drive train models at BMW. Because of the intended use for arbitrary gearbox topologies a signal oriented approach would be not feasible.

The used loss descriptions are either based on the respective geometrical and physical properties, on parameterized semi empirical descriptions, or on tabulated measurement data. All parameters are organized in hierarchical data structures and stored using a data sheet library approach. Since a gearbox may comprise separated subassemblies, for each lossy gearbox component a different lubricant may be chosen and a dedicated temperature may be parameterized.

Each component (e.g. a bearing) contains one (torque independent) or two (torque independent and torque dependent) loss components. These loss components may be specific to a certain component subtype (e.g. a roller bearing) and contain a certain type of loss computation (e.g. according to reference A or B). Each loss component may comprise one or more functions for the computation of the actual drag torque part (e.g. splash loss and ventilation loss). Finally, all loss torques are summed up and routed to the Mechanics.Rotational connectors of the respective component.

Since all formulas in literature are given only for a certain range of operating conditions (e.g. between $1000 \mathrm{rpm}$ and $2500 \mathrm{rpm}$ speed, below $2000 \mathrm{rpm}$, above $2000 \mathrm{rpm}$ ), special care has to be taken to allow usage of the models for zero speed and zero transmitted torque. For practical reasons, the components may optionally be described by a percentage loss factor (e.g. gears) or as ideal, without any losses. Since we are not interested in transient effects, stickslip phenomena have not been modelled. A smooth friction characteristic with limited derivative at zero is used instead.

The strict separation of torque independent and torque dependent losses is useful because in many cases only torque independent measurements are available. The torque dependent losses can be calculated separately and added to the overall loss map.
We made extensive use of class parameterization in order to easily choose among a set of loss types and combinations thereof for each kind of lossy elements in a unified way. The flexible modular structure of the library allows an easy implementation of new components and loss models. Models of the losses of the basic planetary gearings (planet / planet, planet / ring, planet / sun) as parts of arbitrary planetary gearings have been developed recently and are actually under test.

\section{Verification of library models}

\subsection{Component level verification}

For a first validation of the library models, the loss calculations have been compared with the results presented in the literature references which contain loss calculation formulas.

For some components it was also possible to examine special measurements of individual component drag torques. For example, the drag torques of some needle bearings of the gearbox presented later were derived by measurements comparing a complete gearbox and a stripped gearbox where the idler gears of the counter shaft have been removed. Figure 5 shows the calculated drag torques for the regarded idler gears, the sum of these calculated drag torques and the drag torque derived from measurements. The calculation method according to the bearing manufacturer INA [14] was used.

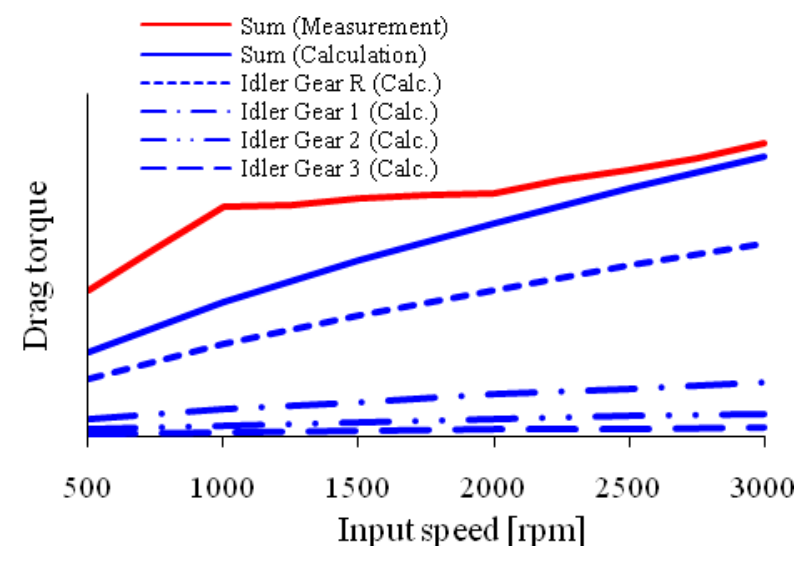

Figure 5: Validation of bearing drag torques of idler gears

The correlation of calculation and measurement is acceptable, especially for speeds above $2000 \mathrm{rpm}$. The fidelity of the bearing drag torques of the idler gears is mainly affected by the relative speed within the bearing, which is rising from the $3^{\text {rd }}$ to the re- 
verse gear. The automated computation of the reaction forces of the tooth engagements and the bearing forces was checked by analytical calculation of several simple load cases.

\subsection{System level verification and sample gear- box loss model}

For the system level verification, a complete model of the new BMW 7 speed double clutch transmission (DCT), which was developed in collaboration with GETRAG and introduced in 2008 (BMW M3, 335i Coupe and Convertible), has been set up. The buildup and the functional principle can be seen in fig. 6 .

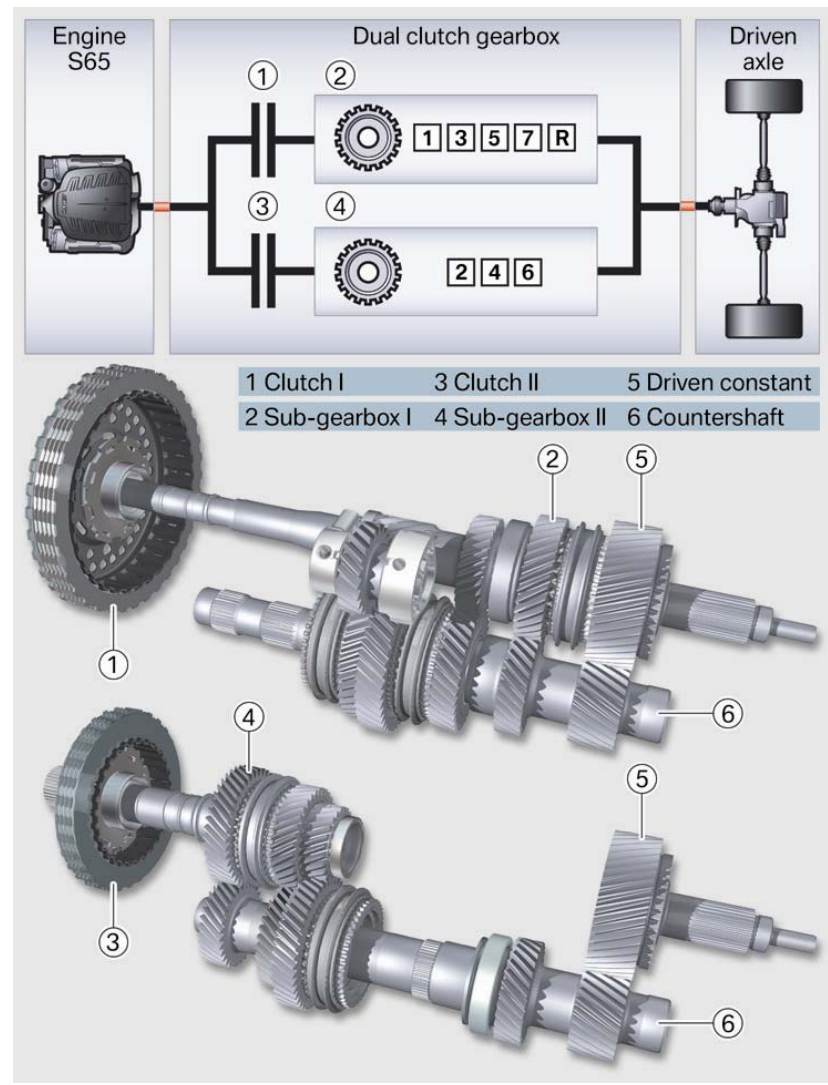

Figure 6: Buildup of the BMW 7 speed double clutch transmission

For the simulation of the drag torques, every lossy component of a gearbox is represented by a corresponding library element. Gears, synchronizers, bearings, seals, rotary unions, clutches and an oil pump have to be considered for loss calculations. The complete Dymola DCT gearbox model is shown in fig. 11.

The gearbox is basically modelled as a rigid multi body system with rotational mechanic flanges at input and output shafts. Inertias of inner shafts and idler gears are reduced to the input and output shafts. The clutches are derived from the original clutch elements of the Modelica standard library. They can be controlled by a torque request signal which is internally interpreted as friction torque (sliding clutch) or maximum transmitted torque (sticking clutch). The gears are shifted by applying forces to the sliding links of the synchronizer units, which are physically modelled including the speed drop caused by friction of the synchronizer cones and the mechanical coupling at the stop position of the sliding links. Since no validated calculation method was available, the losses of the unengaged synchronizers were approximated via drag torque functions depending on the number of cones and the friction radius according to [21], see fig. 7.

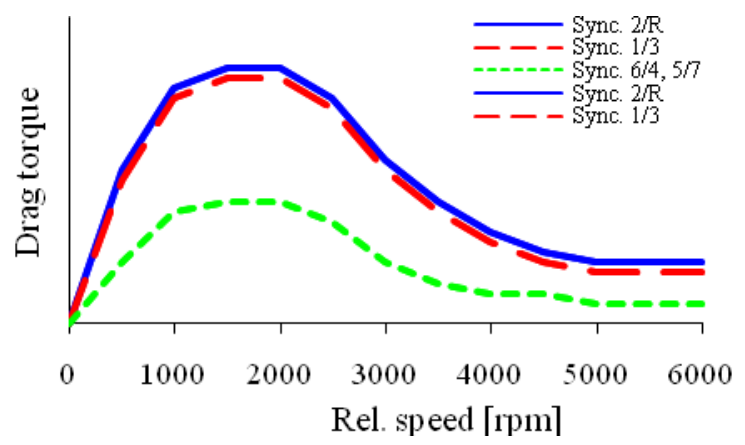

Figure 7: Synchronizer drag torques

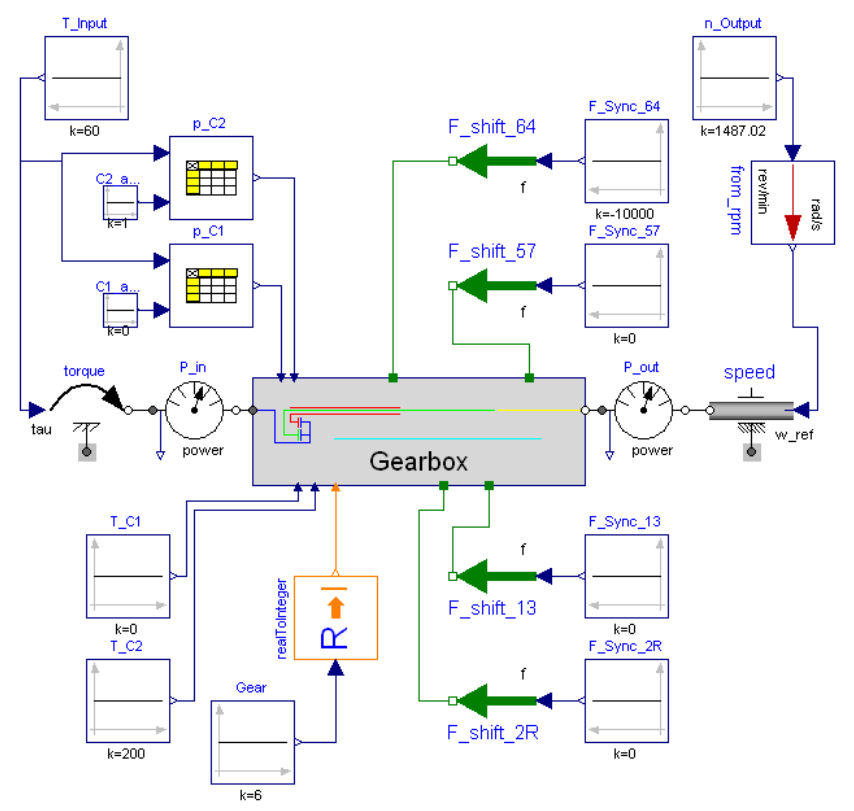

Figure 8: Virtual test bench

The drag torque map of the oil pump was measured separately for several system pressures and could therefore be interpolated from tabulated data depending on input speed and requested system pressure for 
closing the clutches. For the gearings, rotary unions, radial shaft seals and bearings, the loss calculation algorithms described in chapter 2 have been used. In order to calculate the losses of the gearbox for any desired operating point, the gearbox model was integrated in a virtual test bench shown in fig. 8. The actual operating point is adjusted by prescribing the input torque and the output speed. The total losses and the respective overall efficiency can be calculated using the signals of the power sensors at the input and output shaft of the gearbox. Depending on the input torque the pressure level for the clutches, which is mainly influencing the drag torque of the rotary unions, can be derived using simple parameter tables.

\subsection{Simulation results}

For the validation of the simulation model, two test series were available. A comparison to measurements at $80^{\circ} \mathrm{C}$ and for input torques between 10 and $100 \mathrm{Nm}$, varying the input speed from 750 to 2500 $\mathrm{rpm}$, is shown below (figure 9a, 9b). This operating range is very important for the NEDC driving cycle. In the simulation, the loss torques of radial shaft seals were calculated according to Linke [16], the torque independent mesh losses according to Mauz [7], the losses of the needle bearings according to INA/FAG [14] and the losses of the remaining bearings according to the SKF method [15]. In the inactive subgearbox no gear was engaged (no gear prediction). The comparison of measurement and calculation is given in fig. $9 a$ and $9 b$.

Simulation results show a good correlation with measurements. Except for the $7^{\text {th }}$ gear, the maximum differences of measured and calculated drag torques are below $15 \%$. In the $7^{\text {th }}$ gear, which is engaged by direct coupling of input and output shaft, the calculated discrepancy of the two loads $30 \mathrm{Nm}$ and 100 $\mathrm{Nm}$ is significantly less than for the other gears, since no gears are loaded in this case. The remaining torque dependencies are related to the oil pump and the rotary unions. The measurement for the $7^{\text {th }}$ gear $(100 \mathrm{Nm})$ shows an abnormal characteristic, which cannot be explained by the common loss approaches.

Using the validated simulation model it is possible to perform detailed investigations of the partial losses of all gearbox components. Figure 10 shows losses of different components for the $6^{\text {th }}$ gear and $60 \mathrm{Nm}$ input torque. The main amount of losses is caused by the bearings, followed by the oil pump. Only the losses of the synchronizers decrease with rising speed due to the special characteristic shown in fig. 7.
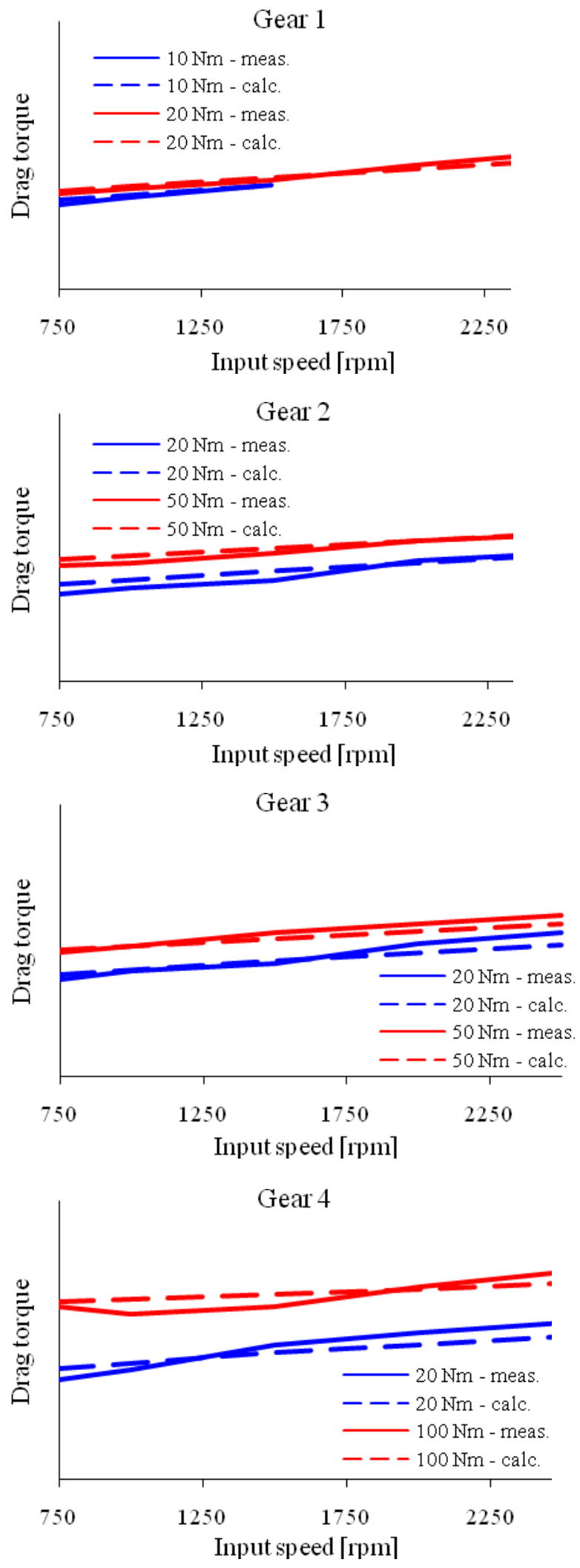

Figure 9a: Comparison of measured and calculated drag torque $\left(80^{\circ} \mathrm{C}\right)$, gears 1 to 4 

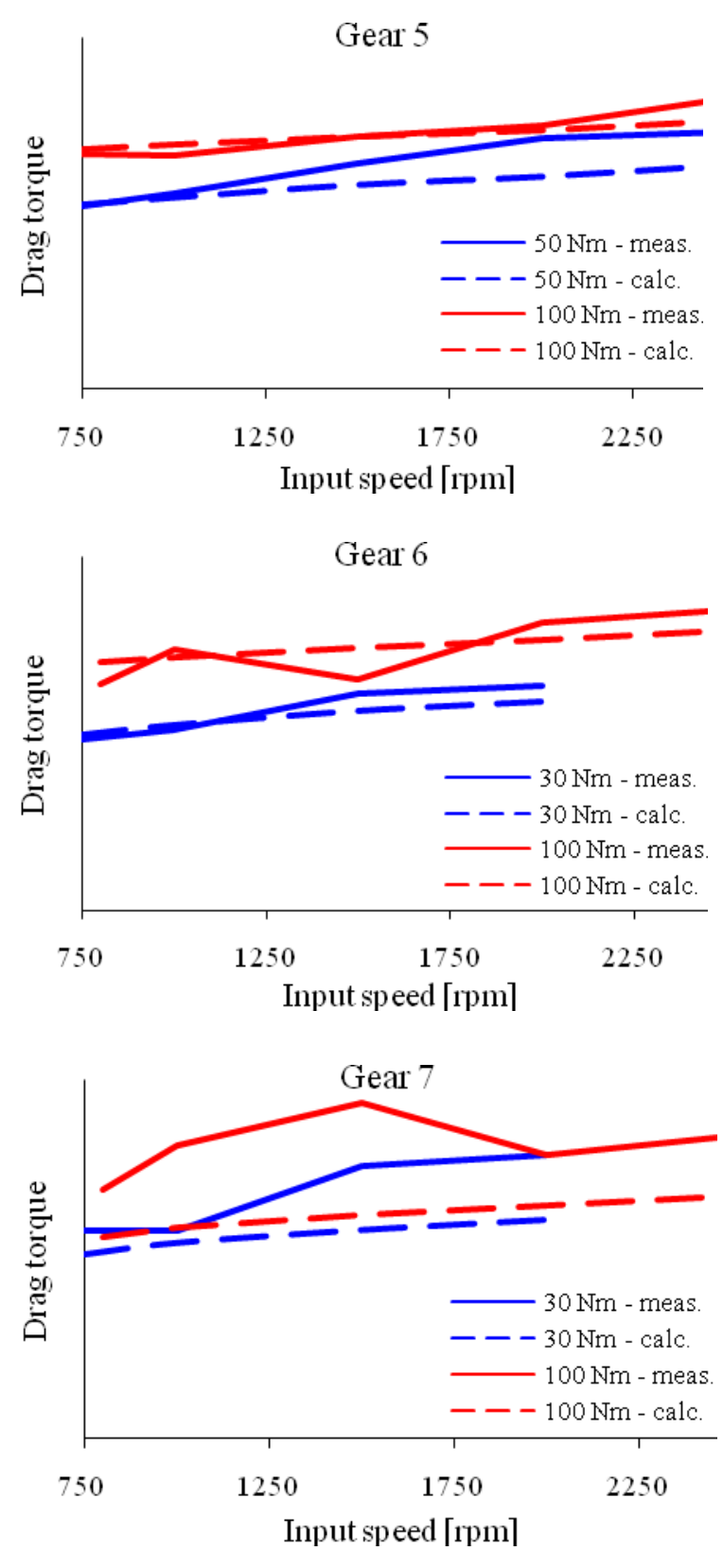

Figure 9b: Comparison of measured and calculated drag torque $\left(80^{\circ} \mathrm{C}\right)$, gears 5 to 7

\section{Outlook on future work}

Our recent investigations focus on 6 and more speed planetary gearboxes. For the calculation of mesh losses and bearing forces, the special relations within the individual planetary gear sets have to be decomposed hierarchically to be able to build models of complex lossy planetary gearboxes out of few base components.

Due to the coupling of many highly nonlinear and in part not continuously differentiable equations de- scribing the drag torques of each single component, numerical problems have to be overcome. They will be investigated in more detail.

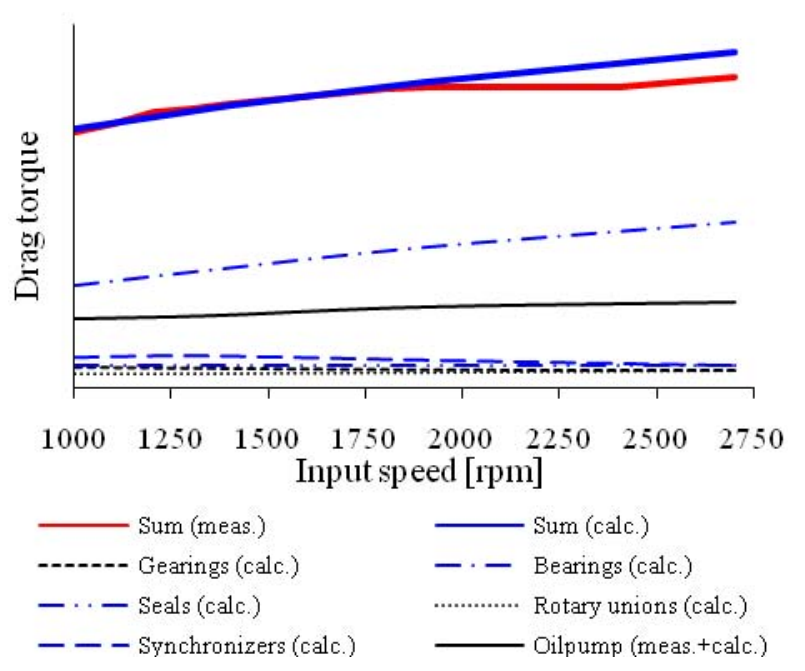

Figure 10: Partial losses $\left(6^{\text {th }}\right.$ gear, $\left.60 \mathrm{Nm}, 40^{\circ} \mathrm{C}\right)$

\section{Acknowledgement}

The authors would like to thank Mr. Stefan Mayr who reviewed the literature, revised the loss formulas for implementation in Modelica, collected parameter data, tested and verified the models on component and system level during his diploma thesis in mechanical engineering.

\section{References}

[1] S. Mayr, Modellierung der Verluste von Getriebekomponenten zur Berechnung von Gesamtgetriebewirkungsgraden. Diplomarbeit TU München und BMW Group, 2008

[2] Forschungsvereinigung Antriebstechnik, Projekt Nr. 69 / I - IV: "Software WTplus"

[3] H. Naunheimer, B. Bertsche, G. Lechner, Fahrzeuggetriebe, Springer, Berlin, 2007

[4] H. Ohlendorf, Verlustleistung und Erwärmung von Stirnrädern. Dissertation TU München, 1958.

[5] L. Schlenk, Untersuchungen zur Fresstragfähigkeit von Großzahnrädern, Dissertation TU München, 1994

[6] A. Wimmer, Verlustoptimierte Verzahnung, FVA Forschungsvorhaben Nr. 372, Heft 731, Abschlussbericht, 2004 
[7] W. Mauz, Hydraulische Verluste von Stirnradgetrieben bei Umfangsgeschwindigkeiten bis $60 \mathrm{~m} / \mathrm{s}$, Dissertation Uni Stuttgart, 1987

[8] Y. Ariura, T. Ueno, The Lubricant Churning Loss and its Behavior in Gearbox in Cylindrical Gear Systems, Journal of Japan Society of Lubrication Engineers, Vol. 20, No 3, 1975

[9] J. Maurer, Ventilationsverluste, FVA Forschungsvorhaben Nr. 44/VI, Heft 432, Abschlussbericht, 1994

[10] Bearinx ${ }^{\circledR}$, Schaeffler KG, Herzogenaurach, Germany

[11] J. Koryciak, Wälzlagerreibmomente, FVAForschungsvorhaben Nr. 382, Heft 823, Abschlussbericht, 2007

[12] A. Palmgren, Neue Untersuchungen über Energieverluste in Wälzlagern, VDI-Berichte 20, S. 117-121, 1957

[13] T.A. Harris, M.N. Kolzalas: Roller Bearing Analysis I+II, 5th edition, Taylor \& Francis, New York, 2007
[14] INA Wälzlager KG, Basic principles rolling bearings, Friction and increases in temperature,

http://medias.schaeffler.de/medias/de!hp.tg.cat tg_rot*CHEBHCFE; bhHLIZo 3h6b?lang=en

[15] SKF Kugellagerfabriken $\mathrm{GmbH}$, Katalog 2004

[16] H. Linke, Stirnradverzahnung. Hanser Verlag, 1996

[17] J. Kettler, Planetengetriebe-Sumpftemperatur, FVA-Forschungsvorhaben Nr. 313, Heft 639, Forschungsbericht, 2002

[18] M. Gronitzki, Untersuchungen zur Funktion und Auslegung von Rechteckdichtringen für Drehdurchführungen, Dissertation Uni Hannover, 2006

[19] Forschungsvereinigung Antriebstechnik, Projekt Nr. 575 / I: "Synchro Schleppmomente"

[20] www.dynasim.com

[21] T. Skubasz: Untersuchungen von Schleppverlusten an Synchronisierungen, Getriebe in Fahrzeugen 2008, VDI-Berichte 2029, VDIVerlag, Düsseldorf, 2008

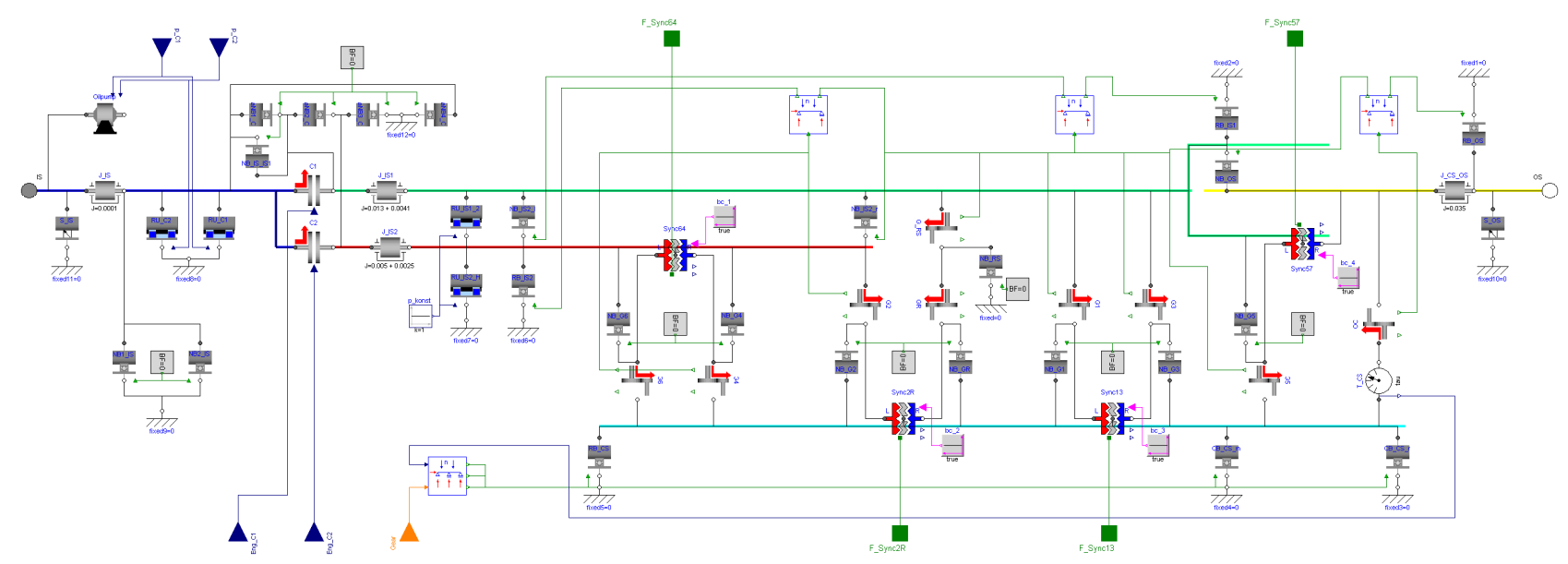

Figure 11: Dymola model of the 7 speed double clutch transmission investigated 